\title{
Business Intelligence Capability, Complementary Resources and Performance among Public Listed Firms in Kenya
}

\author{
Edward Buhasho $^{1}$, Agnes Wausi ${ }^{2} \&$ James Njihia $^{3}$ \\ ${ }^{1}$ Director, Finance and Administration, Blue River Technology Solutions, Nairobi, Kenya \\ ${ }^{2}$ Professor, School of Computing and Informatics, University of Nairobi, Kenya \\ ${ }^{3}$ Professor, School of Business, University of Nairobi, Kenya \\ Correspondence: Edward Buhasho, Finance and Administration, Blue River Technology Solutions, Nairobi, Kenya. \\ E-mail: buhashoe@gmail.com
}

Received: July 9, 2020

Accepted: August 6, 2020

Online Published: August 16, 2020

doi:10.5539/ijbm.v15n9p66

URL: https://doi.org/10.5539/ijbm.v15n9p66

\begin{abstract}
Whereas Business Intelligence initiative has been a primary focus many organisations globally for several years and accounting for billions of dollars in capital expenditure, empirical research remains sparse on the actual impact derived from this investment. Even when the benefits are established, its indirect and delayed impact on business results make it difficult to assess its value. Available literature on how insights triggered by Business Intelligence are transformed into profitable business learning is vague and fragmented. Hence, the main objective of this study was to establish the influence of complementary resources on the relationship between Business Intelligence capability and firm performance. The study used interdisciplinary theories to achieve the research objective, namely, Information systems capability theory and organisational learning. The study was performed using a mixed methods research methodology and cross-sectional approach. Data was collected from 64 public listed companies in Kenya. Findings indicated that complementary resources have a positive and significant impact on the relationship between Business Intelligence capability and performance. The study contributed to theory by building a framework for business intelligence assessment, including factors that significantly lead to improved performance. The results also provide new insights into the existing literature and suggest directions for future research with implications for academia, policymakers and management.
\end{abstract}

Keywords: business intelligence, firm performance, complementary resources, business intelligence capability

\section{Introduction}

The prevailing global business environment is fast changing, complex and characterized by enormous amounts of data originating from multiple sources. Unfortunately, the high volume of data generated cannot be handled by traditional technologies (Sirin \& Karacan, 2017). However, rapid advancement in technologies in the last decade has made processing of data easier, subsequently enabling firms to handle huge volume of data at excessive speed and in various forms such as images and web pages (Sirin \& Karacan, 2017). The concept of Business intelligence (BI) has gained broad acceptance and is deemed as a hallmark to the success of an organization in the advent of globalization (Sebanescu, 2012; Işık, Jones, \& Sidorova, 2013). BI centres on remodelling raw data into usable, valuable and actionable facts (knowledge). New knowledge generated contributes to success of an organization by enabling stakeholders make better decisions (LaValle et al., 2011). A study of over 400 Information and communication Technology (ICT) experts compiled from 93 countries suggested that BI is one of the critical investments in organisations (Arefin et al., 2015). BI global investment was expected to hit \$18.3 billion in 2017 and by the end of 2020, the market is predicted increase to $\$ 22.8$ billion (Moore, 2017).

In Kenya, expenditure on information technology increased by $11 \%$ from $\$ 2.28$ billion in 2016 to $\$ 3.45$ billion in 2017 (Kenya National Bureau of Statistics, 2018). However, in contrast, the performance of corporate institutions, especially public listed firms, has been declining (Kinuthia, 2018). Share index declined from 3607 points to 3285 points in 2018, a 9\% drop (CMA Annual Reports, 2018). Recent profit warnings by listed firms have led to significant decline in share prices, consequently eroding investor's value. Publicly listed firms play a vital role in economic development hence, solid and sustained performance in such companies is imperative. Data is recognized as a resource and can be exploited by the use of BI systems to improve profitability and competitiveness 
(Fink et al., 2017), thereby revising the downward trend of these listed firms. Furthermore, due to shorter product life cycle, change in social values and demographic patterns, these firms operate in a moderate to rapidly changing business environment (Audzeyeva \& Hudson, 2016). Thus, the capability to detect and respond to such changes should be developed.

BI literature is fragmented on how BI impact performance (Audzeyeva \& Hudson, 2016) and lacks a general framework to integrate findings on mediating variables (Trieu, 2017). Empirical studies conducted do not address the element complementary resources adequately (Melville et al., 2004). Thus, Elbashir et al. (2008) reinforced the need for more research focusing on mediators. Mithas et al. (2011) observed that the relationship between BI and performance is influenced by strategic planning and leadership. Yogev et al. (2013) noted that the exploitation and exploration activities in firms have influence on BI-Performance relationship and suggested other factors such as culture ought to be covered in future research.

The contention as observed is further enhanced by Arefin et al. (2015) who argued that complimenting factors such as processes, structure as well as culture and strategy, when evaluated BI impact have not been examined extensively. Trieu (2017) encapsulated this ongoing debate by stating that BI literature is distorted and lacks the general framework to incorporate the findings and systematically guide research. Hence, the objective of this study was to establish the influence of complementary resources on the relationship between BI capability and firm performance to address highlighted inconstancies.

\section{Literature Review}

\subsection{Theories Underpinning the Study}

Theoretical foundation underpinning this study include Information Systems (IS) Capability theory by Peppard \& Ward (2004), and Organisational Learning theory (OLT) advanced by Fiol and Lyles (1985). IS Capability theory accentuates the organisation's ability and capacity to merge, incorporate, evaluate and reconfigure resources as the need arises to gain competitive advantage. Hence, the theory advances the concept of BI capabilities adopted in the research framework. Olszak (2014) pointed out BI capabilities can be combined with available organisation resources, to realise additional (complementary) resources. Complementary relations are dynamic, complex, ambiguous and therefore not easy to be imitated by other firms. OLT opines that for a firm to survive in a live environment, there is a need for a review of actions and processes that contribute to the attainment of the set objectives (Larsen \& Eargle, 2015). Thus, for learning to occur, leaders in the organisation must take deliberate steps to change strategy in response to changing circumstances, connect action to actual result and the result must be quantified. OLT included in order to gain understanding on how output from BI enhances learning, thereby generating new knowledge that leads to improved decisions.

\subsection{BI Capability}

Drawn from IS Capability theory, BI capability refers to critical functionalities that help organizations to continually derive and leverage value through BI (Peppard \& Ward, 2014; Olszak, 2014; Isik et al., 2013). Fink et al. (2017) posit that BI capabilities are the core source of value and often are viewed as catalysts for transforming organisational assets into a competitive advantage. BI capability triggers sustainable competitive advantage and consequently impacting performance (Arefin et al., 2015). Isk et al . (2013) broadened this concept by investigating how capabilities of BI play a role from both a perspective of technical as well as organizational. Nine capabilities involving BI were identified and consequently adopted in this study. Flexibility and risk management support were categorised under organisation perspective. The authors' classified data type quality, interaction, user accessibility, reliability and quality of data sources under technical perspective. Furthermore, a plethora of literature posits that human capital is a critical resource (Bharadwaj, 2000; Stevens, 2010). Hence, human capital was operationalised under analytical skills and BI experience.

\subsection{Firm Performance}

Performance is a multidimensional construct. It centres on the usage of economic performance indicators such as profitability, revenue growth, and market share (Melville et al., 2004). The study adopts Malcom Baldrige National Quality Award (MBNQA) framework that specifically measures IT-enabled information flows (Ghosh et al., 2003). Furthermore, the dimensions used complies with the Wade and Hulland (2004) criteria for appropriate dependent variables to evaluate benefits prompted by IT that should reflect competitiveness and trends. The Malcom framework has been used by other researchers such as by Mithas et al. (2011) to validate the four dimensions of performance adopted in this study. The dimensions include human resource, customer-focus, financial, and organisational effectiveness, to assess BI impact on performance. 


\subsection{Complementary Resources}

Complementary resources are assets that help in generation of technology related benefits (Teece, 1986). Competitive advantage is gained when a firm integrates and deploys available resources (Gupta \& George, 2016; Bharadwaj, 2000). According to Barney (1991), these resources are firm controlled and include wider organisational capabilities that help to realize values from IT investment. Melville et al. (2004) further classified complementary resources to include culture, organizational strategy, structure and decision making process. Denison et al. (2003) posit that culture has four dimensions and include involvement in work, adaptability, mission and consistency. Arefin et al. (2015) observed that the effectiveness of an organisation is drawn from BI systems and depends on corporate culture. Organizational strategy is a plan of achieving organisational goals through interaction with environment. BI systems cannot work in isolation but within the context of competitive environment and organisational factors such as strategy to enhance performance (Arefin et al., 2015). Organization structure refers to forms of authority, communication channels and nature of relationships that exist in an organisation. According to Arefin et al. (2015), the centralisation and decentralization are regular variables connected with the structure.

\subsection{Business Intelligence, Complementary Resources and Firm Performance}

Complementary resources emerge as a synergic outcome between IT and other firm resources. Shollo (2013) conducted empirical study to explore how decision-makers use BI output to shape judgment and make organisational decisions. The findings confirmed that $\mathrm{BI}$ output is utilised by business leaders to tackle illogicality in the organisation decisions and also to enhance legitimacy of their argument. However, the researcher assumed decision makers are always rational hence, limiting generalisation of the findings. Past studies provide proof of incidences where businesses have turned down insights and excellent ideas, only to do exceptionally well when introduced by other organizations. For instance, Xerox 's decision to defer selling computer hardware (Sharma et al., 2014). This study argues intricate processes of making decision are usually involved in generating options, assessing them and committing to a given alternative thus creating a moderating effect.

Imperical information systems research documented a positive effect between firm performance and organizational culture. For example, Rayat and Kelidbari (2017) confirmed culture has a strong influence on BI effectiveness. Further more, the effectiveness of BI has a positive impact on organisational effectiveness. The results were congruous with the investigation of Arefin et al. (2015), who argued that effectiveness of organisations is derived from systems of BI as dependent on culture at corporate level. Sharma et al. (2014) reported that individuals involved in decision making are often constrained by organizational norms that inhibit pursuance of new ideas and can negatively affect the quality and acceptance of decisions, including the firm's capacity to carry out strategic resolutions. Fink et al. (2017) assert that business value of BI depends on the complementarity and compatibility with intended institutional routines through which learning generates new knowledge

Organisation structure is one of the key pillars that create a favourable environment for business information systems success (Arefin et al., 2015; Denison et al.,2003). Empirical study carried out by Arefin et al. (2015) in Bangladesh confirmed that BI systems is more effective in impacting firm performance in a situation where there is decentralized structure and speedy relay of information to top management. The connection between organisation strategy and BI effectiveness is therefore apparent (Rayat \& Kelidbari, 2017). Trieu (2017) noted that there is an absence of research that reviews the complementary connections between BI resources and BI impact to help the organisation better comprehend process of value. BI system provides information to the top management thus enabling them to make sound decisions that have an impact on organisation's performance. Hence, it is hypothesised that:

Ho1 $_{01}$ Complementary resources have no effect on the relationship between BI capability and firm's performance.

\section{Methodology}

\subsection{Research Design and Population}

The study adopted a mixed cross-sectional design, which involves combining elements of qualitative as well as quantitative approaches (Johnson et al., 2007). The rationale to adopting this design include the ability to harness the strength of different methods, provides deeper insights into phenomena that are enigmatic when only using quantitative or qualitative methods, tackle research issues involving real-life understanding of the context, multilevel view and influence of culture (Yu \& Khazanchi, 2017; Johnson et al., 2007). Population for this study were NSE firms totalling 64 as at 31 st December 2018. All listed companies were contacted to participate in the study.

\subsection{Data Collection and Analysis}


Data was collected using a structured questionnaire. Five-point Likert scale with items ranging from ' $1=$ not at all' to ' 5 = very large extent' was selected in preparing the questionnaire. Data was collected from IT Manager/Chief information Officer and Finance Manager/Finance Director in each firm. This is because they were considered to be key informants with information on study objectives (Kim et al., 2011). A total of 64 questionnaires were presented through drop and pick method. The researcher applied the SEM analytical technique to analyse the data, assess the measurement model, confirm the model's fit and check the convergent and discriminating validity of the constructs. Specifically, PLS-SEM was applied to test hypothesis using SmartPLS version 3.0. PLS-SEM is appropriate tool explaining changes in key construct caused by other constructs coupled with ability to function with small sample size (Hair et al., 2014).

\section{Findings}

\subsection{Assessment of the Measurement Models}

Indicator/item reliability, Internal Consistency reliability, convergent validity and discriminant validity were applied to evaluate the reflective measurement model. The indicators that fell short of 0.6 were dropped in evaluating reliability as per the recommendations of Chin (1998) that loadings above 0.6 are ideal. The internal consistency was based on Cronbach's alpha that estimate observed correlations among and within variables (Hair et al., 2017). However, Hair et al. (2017) recommended the use of composite reliability because the alpha of Cronbach is responsive to the number of items in the scale and often underestimate the reliability of internal consistency. The reliability based on composites in study was as follows; BI capability 0.926 , complementary resources 0.904 and financial performance 0.880 . These surpassed the minimum criteria of 0.7 as shown in Table 1 .

Table 1. Construct internal consistency reliability

\begin{tabular}{lll}
\hline Construct & Cronbach's Alpha & Composite Reliability \\
\hline BI Capability (BC) & 0.914 & 0.926 \\
Complementary Resources (CR) & 0.880 & 0.904 \\
Financial Performance (FP) & 0.843 & 0.880 \\
Organisational Capabilities (OC) & 0.877 & 0.906 \\
\hline
\end{tabular}

Convergent validity is the degree to which observed variables are highly correlated with a construct (Wong, 2013). The Average Variance Extracted (AVE) of each latent variable was assessed to verify convergent validity. It is confirmed when AVE values are greater than the acceptable threshold of 0.5 (Wong, 2013; Fornell \& Larcker, 1981). The AVE values for BI capability was 0.513 , complementary resources 0.513 and firm performance 0.514 , above acceptable value of 0.5 . Furthermore, when constructs differ empirically, the discriminant validity is established (Hair et al., 2014). Henseler et al. (2015) offered an alternative technique for assessing discriminant validity known as the heterotrait-monotrait correlation ratio (HTMT). Discriminatory validity is confirmed when HTMT value is below 0.90 (Garson 2016; Henseler et al. 2015). As indicated in Table 2 discriminating validity for all pairs of latent constructs was confirmed.

Table 2. Heterotrait monotrait ratio

\begin{tabular}{llll}
\hline & BC & CR & FP \\
\hline BC & & & \\
CR & 0.816 & & \\
FP & 0.478 & 0.734 & \\
\hline
\end{tabular}

\subsection{Structural Model Evaluation}

Assessment of the hypothesized relationship within the inner model begins after confirmation of the external model's reliability and validity (Hair et al., 2014). Hair et al. (2017) specified that the main criteria for evaluation of the PLS-SEM structural model is coefficients in path showing significance together with $\mathrm{R}^{2}$ values, the effect of $\mathrm{f}^{2}$ size, $\mathrm{Q}^{2}$ vales, and the $\mathrm{q}^{2}$ effect size the effect as explained hereunder. However, the model was first assessed for collinearity issues by applying variance inflation factor (VIF) proposed by Hair et al. (2017). A well-fitted model without multicollinearity should have less than 5.0 VIF coefficients (Garson, 2016). All the VIF values (BI 
capability was 2.916 and complementray resources 2.883 ) were below 5 for the predictor constructs, suggesting lack of multicollinearity.

Predictive Power $\left(\mathrm{R}^{2}\right)$ is a measure of the predictive accuracy of the model. As a general thumb rule, $\mathrm{R}^{2}$ values of 0.75, 0.50, or 0.25 may be defined as significant, moderate, or weak respectively (Hair et al., 2017; Garson, 2016). Predictive power on firm performance was; $\mathrm{R}^{2}=0.458$. This indicates that $45.8 \%$ changes in firm performance can be explained by BI capability and complementary resources. The predictive power was moderate. The Cohen's $\mathrm{f}^{2}$ measure evaluates how strongly an exogenous construct helps to explain identified endogenous construct in relation to $\mathrm{R}^{2}$. According to Cohen (1988), the criteria for assessing $\mathrm{f}^{2}$ are that values of $0.02,0.15$, and 0.35 , representing small, medium, and large effects, respectively. Based on the value extracted, BI capability has a large predictive power on complementary resources ( $f^{2}$ value of 1.242 ). The moderating effect of complementary resources was 0.082 .

Stone-Geisser's $\mathrm{Q}^{2}$ is a metric to test the inner model's predictive relevance by conducting the blindfolding procedure. According to Chin (1998), $\mathrm{Q}^{2}$ values greater than 0 demonstrates the model has predictive relevance to a specific endogenous construct. The values below 0 on the other hand, indicate a lack of predictive significance. The current study resulted in complementary resources $Q^{2}$ value of 0.258 and firm performance value of 0.209 presented in Table 3. Hence, the model shows fairly high degree of predictive relevance for endogenous constructs (that is complementary resources and firm performance).

Table 3. Cross-validated redundancy $\left(\mathrm{Q}^{2}\right)$

\begin{tabular}{llll}
\hline & SSO & SSE & $\mathrm{Q}^{2}(=1-\mathrm{SSE} / \mathrm{SSO})$ \\
\hline Complementary resources & 495 & 367 & 0.258 \\
Firm performance & 385 & 304 & 0.209 \\
\hline
\end{tabular}

The size of the q 2 effect is used to evaluate the relative predictive relevance of exogenous variable. Values of 0.02 , 0.15 , and 0.35 , respectively, demonstrate that an exogenous construct has a small, medium, or large predictive relevance (Hair et al., 2017). $\mathrm{q}^{2}$ effect size for BI capability, complementary resources and organisational capabilities was $0.01,0.09$ and 0.02 respectively. The results indicate complementary resources has size effect 0.09 , implying medium effect on the model predictive relevance if omitted compared to the two other constructs.

\subsection{Hypothesis Testing}

The structural model of this study was evaluated using the path coefficients. The current study applied bootstrapping with 500 resamples to measure $t$ statistics and $P$ values (Chin, 1998). This facilitated the assessment of the path coefficients statistical significance. The mediation effect was assessed using a four-step process (Schultheis, 2016), as shown in Figure 1.

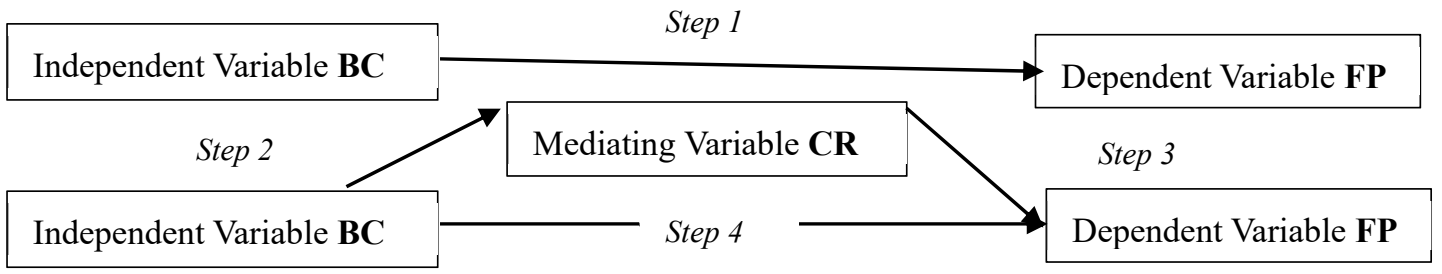

Figure 1. Mediation process

Adopted from MacKinoon, 2007; Sobel, 1990 and Schultheis, 2016.

Step one assessed the significance and nature of the BI capability (BC) and firm performance (FP) relationship. The results showed that there is a significant (t-value $=4.964)$ and a positive relationship (beta value $=0.353$ ), suggesting that $\mathrm{BC}$ has an effect on FP.

Step two then tested the relationship between $\mathrm{BC}$ and a mediating variable, complementary resources (CR). The finding reveals that $\mathrm{BC}$ has an impact on $\mathrm{CR}$ with the results showing that there is a significant $(\mathrm{t}$-value $=12.523)$ and a positive (beta $=0.746$ ) relationship between these two constructs.

Step three tested the effect of the mediating variable CR on the dependent variable FP. The findings showed that 
there is a significant ( $\mathrm{t}$-value $=12.583)$ and a positive $($ beta $=0.683)$ relationship between $\mathrm{CR}$ and FP.

Step four evaluated the influence how BC and FP is mediated by CR where results confirmed a relationship change when $\mathrm{CR}$ is introduced to the equation. The insignificant was observed immediately $\mathrm{CR}$ was considered to $\mathrm{BC}$ and FP interactions $(\beta=-0.103$, t-value $=0.484<1.96 @ 95 \%$ confidence $)$. However, the indirect bath between BC, FP and mediating variable $C R$ was significant and positive $\left(\beta=0.558\right.$, $t$-value $=3.600, p$-value $=0.000, R^{2}=0.458$ and $\mathrm{f}^{2}=0.36$ ). Meanwhile, the path between mediating variable $\mathrm{CR}$ and FP remained positive and significant (tvalue $=4.434$, $p$-value 0.000 and $\beta=0.750$ ). The result complies with condition set by Baron and Kenny (1986) when assessing mediation effect.

The next phase was to determine the magnitude of mediation. This was done by determining the accounted variance for (VAF). It is observed that, VAF below $20 \%$ indicate no mediation, between $20 \%$ and $80 \%$ indicate partial mediation (Hair et al., 2014). Computed VAF $80 \%$ was $61 \%$. Therefore, the conclusion based on the findings is that the relationship between $\mathrm{BC}$ and $\mathrm{FP}$ is partially driven by $\mathrm{CR}$. Hence, the null hypothesis $\left(\mathbf{H}_{01}\right)$ that complementary resources have no mediating effect on the relationship between BI capability and firm's performance is rejected.

\section{Discussion of Findings}

The findings from this study indicate a positive and significant effect of complementary resources on how BI capability relates to firm performance. The findings are in agreement with recent empirical results. For example, results from research conducted by Rayat and Kelidbari (2017) confirmed culture has a significant impact on the effectiveness of BI. Fink et al. (2017) reported that business value of BI depends on the complementarity and compatibility with institutional routines through which learning generates new knowledge. Arefin et al. (2015) established that BI system is more effective in impacting firm's performance in a situation where there is decentralized structure and speedy relay of information to top management. The connection between organisation strategy and BI effectiveness is also apparent in previous studies (Rayat \& Kelidbari, 2017). Empirical research by Isik et al. (2013 confirmed that decision environment does impact the relationship between BI success and capabilities.

Qualitative results of this study further confirmed the role of complementary resources. For example, participants posit that $\mathrm{BI}$ is effective in a rational decision making environment. The value of $\mathrm{BI}$ is negated in an invironment where decisions are based on political interest or intuition. It was also evident from qualitative findings that culture does have an effect on how staff use the application. Organization with conducive culture, enhances staff ability to digest information from various sources and accept positive organisation changes. Participants also stated that $\mathrm{BI}$ value realization is shaped by strategic direction of the organisation. Management provides necessary financial resources in developing BI capabilities. This finding conforms to other previous studies. A study by Bergeron et al. (2004) concluded that firms that perform dismally have weak alignment between IT strategy and business strategy. BI champions were additional complementary resources that emerged from qualitative data analysis. Champions play a vital role in persuading employees to embrace organisation vision and adopt new technology. They are a major part of BI communities of interest inside each department and assist in fostering user excitement to use the application. Yeoh and Koronios (2010) maintained that the role of BI champion is essential to ensure that the organizational problems occurring during BI deployment are handled carefully.

\section{Conclusions and Contributions of the Study}

The results of this study demonstrated a positive mediation effect of complementary resources on the relationship between BI capabilities and firm performance for public listed companies. Therefore, to further improve declining performance, firms should develop additional competencies around prevailing culture in the organisation, review the role of BI champions in ensuring they evangelize the use of BI in their sections, enhance rationality in decision making process and review organisation strategy aimed at securing management support in allocation of resources and setting up a tone at the top on the use of BI across the organisation.

In validating earlier conclusions, the present study findings have contributed to the knowledge gap in regard to the link between BI and firm performance. The results confirmed the complementary resources have significant and positive mediating effect on performance. Moreover, in support of IS capability theory, the complementary impact of constructs in the study is largely attributed to enhanced competitive advantage. Complementary relations are dynamic, complex, ambiguous and therefore not easy to be imitated by other firms. Deployment of an IT innovation alone is not adequate to improve performance (Peppard \& Ward 2004). Therefore, the study advances knowledge on $\mathrm{BI}$ impact by developing an integrated framework that provide a multi-perspective understanding of BI capability for companies listed on NSE. 
This study offers practical insights to managers and leaders of listed public companies in Kenya. The findings of this study provide important factors under complementary resources which include BI champions, culture, decision-making and organizational strategy. For instance, to enhance performance, managers should ensure decision making process is driven by facts in addition to aligning IT strategy to overall business strategy. Management can also use these findings to legitimise selection and development of BI champions across the business. BI champions play a vital role in persuading employees to embrace organisation's vision and adopt new technology. The study also offers valuable insight to top management of listed companies of ensuring they provide unwavering support not only during implementation stage, but throughout the system life cycle. The overall confirmation of a positive and significant impact of BI in performance provides required reference to other individuals spearheading investment in BI solution.

\section{Study's Limitations and Recommendation for Further Research}

Although this study has provided useful insights, it has some limitations. First, the analysis of this study was based on cross-sectional data. While cross-sectional approach is probably used in research because of ingrained cost and time advantages, it does not have the ability to explore all BI benefits. IT related benefits accrue over a long period of time. In future research, the longitudinal research design could be used to improve on reliability of performance data. Second, data was collected from listed firms in Kenya and that could limit generalizability of study findings to other developing countries. Cultural assumptions of a population vary from country to country and hence, the results of the analysis can therefore be restricted to Kenya. Therefore, a similar study can be conducted in other developing countries to further validate highlighted findings.

\section{References}

Arefin, M., Hoque, M., \& Bao, Y. (2015). The impact of Business Intelligence on organization's effectiveness: an empirical study. Journal of Information Technology, 17(3), 263-285. https://doi:10.1108/jsit-09-2014-0067

Audzeyeva, A., \& Hudson, R. (2016). How to get the most from a business intelligence application during the post implementation phase? Deep structure transformation at a UK retail bank. European Journal of Information Systems, 25(1), 29-46. https://doi.org/10.1057/ejis.2014.44

Bagozzi, R. P., \& Yi, Y. (2012). Specification, evaluation, and interpretation of structural equation models. Journal of the academy of marketing science, 40(1), 8-34. https://doi.org/10.1007/s11747-011-0278-x

Barney, J. (1991). Firm resources and sustained competitive advantage. Journal of management, 17(1), 99-120. https://doi.org/10.1016/s0742-3322(00)17018-4

Bergeron, F., Raymond, L., \& Rivard, S. (2004). Ideal patterns of strategic alignment and business performance. Information \& management, 41(8), 1003-1020. https://doi.org/10.1016/j.im.2003.10.004

Bharadwaj, A. S. (2000). A resource-based perspective on information technology capability and firm performance: an empirical investigation. MIS quarterly, 24(1),169-196. https://doi.org/10.2307/3250983

Chin, W. W. (1998). Commentary: Issues and opinion on structural equation modeling. MIS Quartely, 22(1), March, pp. vii-xvi.

CMA Annual Reports. (2018). Retrieved April 10, 2019, from https://www.cma.or.ke/ index.php?option=com phocadownload\&view $=$ category \&id $=13 \&$ Itemid $=212$

Cohen, J. (1988). Statistical power analysis for the behavioral sciences: Abingdon (2nd ed.). New York: Lawrence Erlbaum Associates, Inc.

Denison, D. R., Haaland, S., \& Goelzer, P. (2003). Corporate culture and organizational effectiveness: is there a similar pattern around the world? In Advances in Global Leadership, 3(1), 205-227. https://doi.org/10.1016/s1535-1203(02)03011-3

Elbashir, M. Z., Collier, P. A., \& Davern, M. (2008). Measuring the effects of Business Intelligence systems: The relationship between business process and organizational performance. International Journal of Accounting Information Systems, 9(3), 135-153. https://doi.org/10.1016/j.accinf.2008.03.001

Fink, L., Yogev, N., \& Even, A. (2017). Business intelligence and organizational learning: An empirical investigation of value creation processes. Information \& Management, 54(1), 38-56. https://doi.org/10.1016/j.im.2016.03.009

Fiol, M., \& Lyles, M. (1985). Organisational learning. Academy of Management Review, 10(4), 803-813. https://doi.org/10.1016/j.accinf.2008.03.001

Fornell, C., \& Larcker, D. F. (1981). Evaluating structural equation models with unobservable variables and 
measurement error. Journal of marketing research, 18(1), 39-50. https://doi.org/10.1177/002224378101800104

Garson, G. D. (2016). Partial least squares: Regression and structural equation models. Asheboro: Statistical Associates Publishers.

Ghosh, S., Handfield, R. B., Kannan, V. R., \& Tan, K. C. (2003). A structural model analysis of the Malcolm Baldrige National Quality Award framework. International Journal of Management and Decision Making, 4(4), 289-311. https://doi.org/10.1504/ijmdm.200 3.003996

Gupta, M., \& George, J. F. (2016). Toward the development of a big data analytics capability. Information \& Management, 53(8). https://doi.org/10.1016/j.im.2016.07.004

Hair Jr, J. F., Hult, G. T., Ringle, C., \& Sarstedt, M. (2014). A primer on partial least squares structural equation modeling (PLS-SEM). Los Angeles: SAGE Publication.

Hair Jr, J. F., Hult, G. T., Ringle, C., \& Sarstedt, M. (2017). A primer on partial least squares structural equation modeling (PLS-SEM). Thousand Oaks, California: SAGE Publications.

Işı1k, Ö., Jones, M. C., \& Sidorova, A. (2013). Business Intelligence success: The roles of BI capabilities and decision environments. Information \& Management, 50(1), 13-23. https://doi.org/10.1016/j.im.2012.12.001

Johnson, R. B., Onwuegbuzie, A. J., \& Turner, L. A. (2007). Toward a definition of mixed methods research. Journal of mixed methods research, 1(2), 112-133. https://doi.org/10.1177/1558689806298224

Kaplan, R., \& Norton, P. (1996). The Balanced Score Card: Translating Strategy into action. Boston MA: Harvard Business School Press.

Kenya National Bureau of Statistics. (2018). Economic survey. Retrieved January 20, 2019, from https://www.knbs.or.ke/?wpdmpro=economic-survey-2018

Kim, G., Shin, B., Kim, K. K., \& Lee, H. G. (2011). IT capabilities, process-oriented dynamic capabilities, and firm financial performance. Journal of the association for information systems, 12(7), 487-517. https://doi.org/10.17705/1jais.00270

Kinuthia, K. (2018). Firms that issued profit warning in 2018. Business Daily. Retrieved January 11, 2019, from https://www.businessdailyafrica.com/corporate/ this-year/4003102-4879114-14d53liz/index.html

Larsen, K. R., \& Eargle, D. (2015). Retrieved March 13, 2019, from https://is.theorizeit.org/wiki/Organizational_learning_theory.

LaValle, S., Lesser, E., Shockley, R., Hopkins, M. S., \& Kruschwitz, N. (2011). Big data, analytics and path from insights to value. MIT sloan management review, 52(2), 21-32.

Melville, N., Kmerner, K., \& Gurbaxani, V. (2004). Review: Information Technology and Organizational Performance: An integrative model of IT business value. MIS Quarterly, 28(2), 283-322. https://doi.org/10.2307/25148636

Mithas, S., Ramasubbu, N., \& Sambamurthy, V. (2011). How Information Management Capability Influences Firm Performance. MIS quarterly, 35(1), 237-256. https://doi.org/10.2307/23043496

Moore, S. (2017). Newsroom. Retrieved November 12, 2018, from https://www.gartner.com/newsroom/id/3612617

Olszak, C. M. (2014). Towards an Understanding Business Intelligence. A dynamic capability-based framework for Business Intelligence. Federated Conf. on IEEE, 2(1), 1103-1110. https://doi.org/10.15439/2014f68

Peppard, J., \& Ward, J. (2004). Beyond strategic information systems: towards an IS capability. The Journal of Strategic Information Systems, 13(2), 167-194. https://doi.org/10.1016/j.jsis.2004.02.002

Rayat, M., \& Kelidbari, H. R. (2017). The Effects of Business Intelligence on the Effectiveness of the Organization. Review of European Studies, 9(3), 176. https://doi.org/ 10.5539/res.v9n3p176

Schultheis, M. P. (2016). The impact of Business Intelligence systems on the perceived quality of strategic decision making. Unpublished $\mathrm{PhD}$ Thesis, Curtin University. Retrieved from https://pdfs.semanticscholar.org/6b6f/5ee35703011dcad6fce3e612fa6c86a8296f.pdf

Sebanescu, L. (2012). Necessity to Implement a Business Intelligence Solution for the Management optimization of a Company. USV Annals of Economics \& Public Administration, 12(16), 144-122. 
Sharma, R., Mithas, S., \& Kankanhalli, A. (2014). Transforming Decision-making Processes: a Research agenda for understanding the Impact of Business Analytics on Organizations. European Journal of Information Systems, 23(1), 433-441. https://doi.org/10.1057/ejis.2014.17

Shollo, A. (2013). The Role of Business Intelligence in Organizational Decision-making. School of Economics and Management (1st ed.). Denmark: Copenhagen Business School.

Sirin, E., \& Karacan, H. (2017). A Review on Business Intelligence and Big Data. International Journal of Intelligent Systems and Applications in Engineering, 5(4), 206-215. https://doi.org/10.18201/ijisae.2017533861

Sobel, M. E. (1990). Effect analysis and causation in linear structural equation models. Psychometrika, 55(3), 495515. https://doi.org/10.1007/bf02294763

Stevens, R. H. (2010). Managing human capital: How to use knowledge management to transfer knowledge in today's multi-generational workforce. International Business Research, 3(3), 77. https://doi.org/10.5539/ibr.v3n3p77

Teece, D. J. (1986). Profiting from technological innovation: Implications for integration, collaboration, licensing and public policy. Research policy, 15(6), 285-305. https://doi.org/10.1016/0048-7333(86)90027-2

Trieu, V. H. (2017). Getting value from Business Intelligence systems: A review and research agenda. Decision Support Systems, 93(1), 111-124. https://doi.org/10.1016/j.dss. 2016.09.019

Urbach, N., \& Ahlemann, F. (2010). Structural equation modeling in information systems research using partial least squares. Journal of Information technology theory and application, 11(2), 5-40.

Wade, M., \& Hulland, J. (2004). The resource-based view and information systems research: Review, extension, and suggestions for future research. MIS quarterly, 28(1), 107-142. ttps://doi.org/10.2307/25148626

Wong, K. K. (2013). Partial least squares structural equation modeling (PLS-SEM) techniques using SmartPLS. Marketing Bulletin, 24(1), 1-32.

Yeoh, W., \& Koronios, A. (2010). Critical success factors for Business Intelligence Systems. Journal of Computer Information Systems, 30(2), 23-32. https://doi.org/10.1080/08874417.2010.11645404

Yogev, N., Even, A., \& Fink, L. (2013). How Business Intelligence Creates Value. International Journal of Business Intelligence Research, 4(3), 16-31. https://doi.org/10.4018/ijbir.2013070102

Yu, X., \& Khazanchi, D. (2017). Using Embedded Mixed Methods in Studying IS Phenomena: Risks and Practical Remedies with an Illustration. Communications of the Association for Information Systems, 41(1), 555-595. https://doi.org/10.17705/1 cais.04102

\section{Copyrights}

Copyright for this article is retained by the author(s), with first publication rights granted to the journal.

This is an open-access article distributed under the terms and conditions of the Creative Commons Attribution license (http://creativecommons.org/licenses/by/4.0/). 